\title{
Were James Bond's drinks shaken because of alcohol induced tremor?
}

\author{
(C) (ब) OPEN ACCESS
}

\author{
Graham Johnson ST5 emergency medicine ${ }^{1}$, Indra Neil Guha clinical associate professor of \\ hepatology ${ }^{2}$, Patrick Davies consultant paediatric intensive care ${ }^{3}$
}

${ }^{1}$ Emergency Department, Royal Derby Hospital, Derby; ${ }^{2}$ NIHR Nottingham Digestive Diseases Biomedical Research Unit, University of Nottingham; ${ }^{3}$ Paediatric Intensive Care Department, Nottingham University Hospitals NHS Trust, Nottingham

\begin{abstract}
Objective To quantify James Bond's consumption of alcohol as detailed in the series of novels by lan Fleming.

Design Retrospective literature review.

Setting The study authors' homes, in a comfy chair.

Participants Commander James Bond, 007; Mr lan Lancaster Fleming.

Main outcome measures Weekly alcohol consumption by Commander Bond.

Methods All 14 James Bond books were read by two of the authors. Contemporaneous notes were taken detailing every alcoholic drink taken. Predefined alcohol unit levels were used to calculate consumption. Days when Bond was unable to consume alcohol (such as through incarceration) were noted.

Results After exclusion of days when Bond was unable to drink, his weekly alcohol consumption was 92 units a week, over four times the recommended amount. His maximum daily consumption was 49.8 units. He had only 12.5 alcohol free days out of 87.5 days on which he was able to drink.

Conclusions James Bond's level of alcohol intake puts him at high risk of multiple alcohol related diseases and an early death. The level of functioning as displayed in the books is inconsistent with the physical, mental, and indeed sexual functioning expected from someone drinking this much alcohol. We advise an immediate referral for further assessment and treatment, a reduction in alcohol consumption to safe levels, and suspect that the famous catchphrase "shaken, not stirred" could be because of alcohol induced tremor affecting his hands.
\end{abstract}

\section{Introduction}

Excess alcohol consumption is a societal and health problem throughout the world. Around 4\% of deaths worldwide are related to alcohol, with 2.5 million deaths a year attributable to its use. ${ }^{1}$ Death is most commonly caused by injury, liver cirrhosis, poisoning, and malignancy. In the entertainment world, however, excess alcohol consumption is often portrayed in a positive, even glamorous, light. Of particular note are the drinking habits of James Bond, the quintessential British spy in the novels of Ian Fleming. He is renowned for enjoying cigarettes, alcohol, and women, with a catchphrase of "vodka martini-shaken, not stirred."

James Bond has often been seen as a strong role model. He is admired for his performance under pressure and his ability to be master of all situations he encounters. We were struck, while reading the original James Bond books, that his alcohol consumption seemed rather high and wondered whether he would realistically have the capacity to perform (in all aspects of his life $)^{23}$ at his high level of alcohol intake. Previous analyses of Bond's drinking behaviour have examined the types of alcohol he has drunk and the total number of drinks ${ }^{45}$ but have never studied the number of units of alcohol this represents and the potential health effects of this.

Ideally vodka martinis should be stirred, not shaken. ${ }^{6}$ That Bond would make such an elementary mistake in his preferences seemed incongruous with his otherwise impeccable mastery of culinary etiquette. We examined Bond's alcohol consumption to determine whether he might have been unable to stir his drinks because of the persistent shaking of alcohol induced tremor, making it more socially acceptable to ask for his drinks "shaken, not stirred." 


\section{Methods}

Two authors read all 14 original James Bond books either on paper or on a Kindle (Amazon UK) device between January and July 2013. They kept contemporaneous notes of all alcohol consumption, as documented in the books. Each author read seven books.

Bond's alcohol intake was calculated by the number of days on which action was described. We used pre-formed definitions of units (table $1 \Downarrow$ ), based on definitions provided by www.nhs.uk/ alcohol, ${ }^{7}$ a United Kingdom National Health Service (NHS) alcohol awareness website. In the UK a unit of alcohol is defined as $10 \mathrm{ml}$ or $8 \mathrm{~g}$ of pure ethanol. For cocktails we obtained recipes from Wikipedia. Spirit volumes were taken from previous research into actual poured volumes. ${ }^{8-10}$ When drinks were shared, an equal split was presumed at all times. The last five terms in table 1 were used only if there was no specific mention of which drinks were consumed. We considered the unit and quantities to be reasonable but relatively conservative estimates in the context of his overall drinking habits. It is likely that these are an underestimate rather than an overestimate of his intake on these few occasions.

Data were then analysed by day. When days were not described or described in only brief detail, they were not taken in to account. Days when Bond was unable to drink (usually because of incarceration or injury) were logged.

We excluded The Spy Who Loved Me from analysis as it is written in the first person by a waitresses involved with the criminal underworld, and Bond appears for only eight hours as a peripheral figure. The 14th book, Octopussy and the Living Daylights is a compendium of short stories and was also excluded as it is not one coherent detailed story.

\section{Results}

Across 12 of the 14 books, 123.5 days were described, though Bond was unable to consume alcohol for 36 days because of external pressures (admission to hospital, incarceration, rehabilitation). During this time he was documented as consuming 1150.15 units of alcohol (table 2 ) $\Downarrow$. Taking into account days when he was unable to drink, his average alcohol consumption was 92 units a week (1150 units over 87.5 days). Inclusion of the days incarcerated brings his consumption down to 65.2 units a week. His maximum daily consumption was 49.8 units (From Russia with Love day 3). He had 12.5 alcohol free days out of the 87.5 days on which he was able to drink.

Furthermore, when we plotted Bond's alcohol consumption over time, his intake dropped in the middle of his career but gradually increased towards the end (figure $\downarrow$ ). This consistent but variable lifetime drinking pattern has been reported in patients with alcoholic liver disease. ${ }^{11}$

\section{Statistics}

Descriptive statistics alone have been performed.

\section{Discussion}

We have shown that James Bond's alcohol consumption, while on his various missions for Her Majesty's Secret Service is, on average, between 65 and 92 units a week. There is only one indication of his alcohol consumption while not on a mission. During a medical assessment in Thunderball he is documented as drinking half a bottle of spirits a day, equivalent to 105 units a week. There are also occasional references to hangovers during non-mission times in the books. We therefore conclude that his drinking during missions is roughly comparable with his "office days."

Many studies have shown that people generally underestimate their alcohol consumption by around 30\%, implying that Bond's could be as high as 130 units a week. It is unclear whether having a third party describing one's alcohol intake would make stated consumption more or less accurate. Recent research implies that half of all alcohol sold is not accounted for by health surveys, so actual consumption could even be double that claimed. ${ }^{8-10} \mathrm{We}$ are unaware of any studies that have shown an overestimation of alcohol consumption. Similarly, when we had to estimate Bond's consumption (such as "visited a bar") we have been deliberately conservative. We are therefore confident that our estimates are at the lower end of the truth.

UK NHS recommendations for alcohol consumption state that an adult male should drink no more than 21 units a week, with no more than 4 units on any one day, and at least two alcohol free days a week. ${ }^{12}$ James Bond's drinking habits are well in excess of each of these three parameters. This level of consumption makes him a category 3 drinker $(>60 \mathrm{~g}$ alcohol/day) and therefore in the highest risk group for malignancies, depression, hypertension, and cirrhosis. ${ }^{13}{ }^{14} \mathrm{He}$ is also at high risk of suffering from sexual dysfunction,,${ }^{15}$ which would considerably affect his womanising.

Data on the average life expectancy of real world secret agents are, not surprisingly, difficult to find. Although some secret service deaths are high profile, there are limited data on a robust denominator for this population. In Moonraker, Bond reflects that he would probably be killed before the age of 45 (the age of mandatory retirement from the "00" section of MI6). Should he not be "killed in action," his risk of developing many serious pathologies is high.

Deaths from liver cirrhosis occur at a relatively young age in the UK; an average of 59 years, in stark contrast to the other major causes of mortality including respiratory and cardiovascular disease. Rehm and colleagues have shown a dose:response relation with alcohol and development of cirrhosis. Drinking between 65 and 92 units of alcohol a week equates to between $74 \mathrm{~g}$ and $105 \mathrm{~g}$ of alcohol a day, giving Bond a relative risk of developing liver cirrhosis of between 7 and 16 compared with a lifetime abstainer. ${ }^{14}$ Work by Hart and colleagues would suggest that his relative risk of all cause mortality is greater than 1.74 (95\% confidence interval 1.47 to $2.06)$ and particularly from stroke $(2.33,1.31$ to 4.14$)$ and alcohol related causes $(3.72,98$ to 7.00$) .{ }^{16}$. Presuming survival despite the high risk nature of his profession, we anticipate that James Bond's life expectancy would be significantly reduced. In fact, the author Ian Fleming died aged 56 of heart disease after a life notable for alcohol and tobacco excess. We suspect that Bond's life expectancy would be similar.

High stress jobs are often associated with high alcohol intake, ${ }^{17}$ and it would therefore be logical to assume that these professions are also associated with a high alcohol related mortality. An analysis by the website businessinsider.com, however, showed that actually bartenders and shoe-machine operators had the highest alcohol related deaths. ${ }^{18}$ They identified that sailors were the sixth highest risk, with a relative risk of 1.75 for an alcohol related death. Bond was, first and foremost, a sailor, so his drinking habits might have their root in his original profession. It is well recognised that alcohol increases the risk of driving related incidents, and this risk increases from blood alcohol level of $0.04 \%$. The UK sets its limit at $0.08 \%$, which is the same as the US, but higher than that of much of Europe and Australia. ${ }^{1}$ No such limits existed in the 1950 s and throughout 
the books Bond is noted to have several drinks, enough to put him well over this limit and then drive. In Goldfinger, for example, he drinks 18 units while having drinks and dinner with Auric Goldfinger before then driving home. In Casino Royale he drinks over 39 units before engaging in a high speed car chase, losing control, and spending 14 days in hospital. We hope that this was a salutatory lesson.

Such behaviour is typical of Bond. Despite his alcohol consumption, he is still described as being able to carry out highly complicated tasks and function at an extraordinarily high level. This is likely to be pure fiction.

It was noted that Bond's intake decreased in the middle part of his career but increased again towards the latter years. Consistently high but variable levels of drinking have already been documented in heavy drinkers,${ }^{11}$ but one potential reason for the increase in the later books could be the death of his new wife in On Her Majesty's Secret Service in 1963. This could explain the peak of his drinking in 1964, as he tried to find a quantum of solace in alcohol, before returning to his more usual level of consumption in 1965 when he was pitted against Francisco Scaramanga. It would also match the findings of Eigenbrodt and colleagues that in all ethnicities together alcohol intake will slightly decrease with age, but in white men it will actually increase, at least up until the age of $60 .{ }^{19}$

\section{Connoisseur or alcoholic?}

A commonly used screening tool to identify alcohol dependence is the "CAGE" questionnaire, ${ }^{20}$ where two yes responses should prompt further investigation:

- Have you ever felt you needed to Cut down on your drinking?

- Have people Annoyed you by criticising your drinking?

- Have you ever felt Guilty about drinking?

- Have you ever felt you needed a drink first thing in the morning (Eye opener) to steady your nerves or to get rid of a hangover?

Applying these to Bond, the authors would score him 3 out of 4. In "Thunderball" he recognises his high alcohol intake and that he feels better drinking less. He also admits to having an eye opener on some mornings (the "Prairie Oyster"). Also in Thunderball, together with the Living Daylights, he becomes annoyed when challenged about his drinking by his boss " $M$ ". It is likely that an international spy and assassin cannot spend too much time worrying about remorse, so we are not surprised that there are no documented instances of alcohol associated guilt.

The most common cause of tremor is essential tremor. ${ }^{21}$ This is typically postural and will most commonly affect the upper limbs, although lower limb involvement is recognised. The role of alcohol is somewhat uncertain, with some evidence that in lower doses it can be beneficial in essential tremor, while others propose that those with high alcohol consumption are four times more likely to suffer with essential tremor. ${ }^{22}$

Cerebellar lesions are well known to cause an intention tremor and cerebellar tremor is considered a distinct clinical entity. ${ }^{23}$ While strokes are a more common cause of cerebellar lesions (of which Bond is at increased risk ${ }^{13}$ ), chronic exposure to toxins, such as alcohol, that cause more generalised damage to the cerebellum can also cause a cerebellar tremor. We have shown that Bond's alcohol intake is of sufficiently high frequency and duration to cause such cerebellar damage.

\section{Limitations}

Ideally each of the authors would have read all of the books and reached their own total for Bond's alcohol consumption, allowing a $\kappa$ statistic to be calculated and a consensus amount for each book. Unfortunately limited resources and other clinical, social, intellectual, and cultural commitments meant a more pragmatic approach had to be taken, and seven books each were allocated over the six month study period.

On several occasions estimates of consumption have had to be used as Mr Fleming was not precise with his writing. The authors have taken reasonable measures to ensure that, when necessary, conservative estimates have been made. Of the total 1150 units drunk, only 190 units (16.5\%) were accounted for by these terms, therefore if the estimations were inaccurate this would make a minimal change to the total. Similarly, when it was mentioned that drinks were shared, we thought it appropriate to assume an equal share of the drinks, regardless of who he was sharing with.

One of the study authors was familiar with the books and had read them before the study period. While it was noted at that time that the consumption of alcohol was an important part of Bond's life, detailed notes on the magnitude of his consumption were not taken. It did, however, inform the original study idea.

\section{Conclusions}

James Bond's weekly alcohol intake is over four times the advisable maximum alcohol consumption for an adult male. He is at considerable risk of developing alcoholic liver disease, cirrhosis, impotence, and other alcohol related health problems, together with being at serious risk of injury or death because of his drinking. Although we appreciate the societal pressures to consume alcohol when working with international terrorists and high stakes gamblers, we would advise Bond be referred for further assessment of his alcohol intake and reduce his intake to safe levels.

We conclude that James Bond was unlikely to be able to stir his drinks, even if he would have wanted to, because of likely alcohol induced tremor. $\Downarrow$

Contributors: GJ read half of the books, and drafted and edited the paper. ING edited the paper and added much hepatology advice. PD developed the hypothesis, read half the books, and edited the manuscript.

Funding: No funding was sought for this study. The original books were already owned by two of the study authors.

Competing Interests: All authors have completed the ICMJE uniform disclosure form at www.icmje.org/coi_disclosure.pdf and declare: no support from any organisation for the submitted work; no financial relationships with any organisations that might have an interest in the submitted work in the previous three years; no other relationships or activities that could appear to have influenced the submitted work.

Ethical approval: The impact of this study on fictional British spies was thought to be minimal and therefore ethical approval was not sought for this study.No consent has been sought from the Commander Bond chronicled in the original lan Fleming novels. The barrier to this chiefly being his fictional nature meaning he is unable to give valid consent.

Data sharing: Technical appendix and dataset are available from the corresponding author.

WHO 2011. Global status report on alcohol and health www.who.int/substance_abuse/ publications/global_alcohol_report/msbgsruprofiles.pdf.

2 O'Farrell TJ, Choquette KA, Cutter HS, Birchler GR. Sexual satisfaction and dysfunction in marriages of male alcoholics: comparison with nonalcoholic maritally conflicted and nonconflicted couples. J Stud Alcohol 1997;58:91-9. 


\section{What is already known on this topic}

Author and ex-Naval intelligence operative lan Lancaster Fleming died at a relatively young age from a myocardial infarction and enjoyed smoking and drinking to excess. It has been postulated that the habits of his literary character, James Bond, had habits similar to his own

James Bond's consumption and in depth knowledge of a wide variety of alcoholic drinks is well documented. What has been unclear to date is whether he was more a connoisseur or a chronic alcoholic

\section{What this study adds}

Bond consumed an average of 92 units a week, yet he is still described as being the "best shot in the Secret Service." People who drink at this level are severely functionally inhibited and unless this refers to shots of various spirits, this assertion is likely to be pure fantasy The security of the British Isles depends on our Secret Service agents performing at their highest ability; quantifying the alcohol intake of their "top" spy might be an indicator of the consumption of other agents and should prompt further enquiry and support

3 Fahrner EM. Sexual dysfunction in male alcohol addicts: prevalence and treatment. Arch Sex Behav 1987;16:247-57.

4 James Bond Memes. Drinking for England: analysis of 007's alcohol consumption. http:/ /jamesbondmemes.blogspot.co.uk/2011/11/drinking-for-england-analysis-of-007s.html.

5 About.com. 10 James Bond Cocktails. What does James Bond Drink? http://cocktails. about.com/od/history/tp/jamesbond_cocktails.htm.

6 Daily Telegraph. www.telegraph.co.uk/foodanddrink/9043420/Perfect-vodka-martinishould-be-stirred-with-a-wooden-spoon-claim-scientists.htm.

7 NHS Choices. www.nhs.uk/livewell/alcohol/Pages/Alcoholhome.aspx.

8 Boniface S, Shelton N. How is alcohol consumption affected if we account for under-reporting? A hypothetical scenario. Eur J Public Health 2013;23:1076-81. http:/ eurpub.oxfordjournals.org/content/early/2013/02/25/eurpub.ckt016.abstract.

9 Boniface S, Kneale J, Shelton N. Actual and perceived units of alcohol in a self-defined "usual glass" of alcoholic drinks in England. Alcohol Clin Exp Res 2013;37:978-83.

10 UCL News. www.ucl.ac.uk/news/news-articles/1302/27022013-Alcohol-consumptionmuch-higher-than-reported-in-England-Boniface.

11 Hatton J, Burton A, Nash H, Munn E, Burgoyne L and Sheron N. Drinking patterns, dependency and life-time drinking history in alcohol-related liver disease. Addiction 2009;104:587-92.

12 Recommended safe limits of alcohol. www.patient.co.uk/health/Recommended-SafeLimits-of-Alcohol.htm.

13 Rehm J, Gmel G, Sempos CT, Trevisan M. Alcohol-related morbidity and mortality. Alcohol Res Health 2003;27:39-51.

14 Rehm J, Taylor B, Mohapatra S, Irving H, Baliunas D, Patra J, et al. Alcohol as a risk factor for liver cirrhosis: a systematic review and meta-analysis. Drug Alcohol Rev 2010;29:437-45.

15 Arackal BS, Benegal V. Prevalence of sexual dysfunction in male subjects with alcohol dependence. Indian J Psychiatry 2007:49:109-12.

16 Hart CL, Smith GD, Hole DJ, Hawthorne VM. Alcohol consumption and mortality from all causes, coronary heart disease, and stroke: results from a prospective cohort study of Scottish men with 21 years of follow up. BMJ 1999;318:1725.
17 Azagba S, Sharaf M. The effect of job stress on smoking and alcohol consumption. Health Econ Rev 2011;1:15.

18 The 17 jobs where you're most likely to become an alcoholic. www.businessinsider.com most-alcoholic-jobs-2011-10?op=1

19 Eigenbrodt ML, Mosley TH Jr, Hutchinson RG, Watson RL, Chambless LE, Szklo M. Alcohol consumption with age: a cross-sectional and longitudinal study of the atherosclerosis risk in communities (ARIC) study, 1987-1995. Am J Epidemio 2001;153:1102-11.

20 Ewing, John A. Detecting alcoholism: the CAGE questionnaire. JAMA 1984;252:1905-7.

21 Bares M, Husarova I, Lungu OV. Essential tremor, the cerebellum, and motor timing: towards integrating them into one complex entity. Tremor Other Hyperkinet Mov (N Y) 2012;2:pii:tre-02-93-653-1. Epub 2012 Sep 12.

22 Louis ED, Benito-Leon J, Bermejo-Pareja F. Population-based study of baseline ethano consumption and risk of incident essential tremor. J Neurol Neurosurg Psychiatry 2009;80:494-7.

23 National Institute for Neurological Disease and Stroke. Tremor fact sheet. www.ninds.nih. gov/disorders/tremor/detail_tremor.htm.

Accepted: 27 November 2013

\section{Cite this as: BMJ 2013:347:f7255}

This is an Open Access article distributed in accordance with the Creative Commons Attribution Non Commercial (CC BY-NC 3.0) license, which permits others to distribute, remix, adapt, build upon this work non-commercially, and license their derivative works on different terms, provided the original work is properly cited and the use is non-commercial. See: http://creativecommons.org/licenses/by-nc/3.0/. 


\section{Tables}

Table 1| Alcoholic unit definitions by drink or activity

\begin{tabular}{lcc} 
Type of drink & Measure & Alcohol units \\
Wine & One bottle & 9 \\
\hline Wine & Carafe & 12 \\
\hline Spirits neat & Regular measure & 1.25 \\
\hline Spirits mixed & Regular measure & 1.8 \\
\hline Spirits neat & Large, double, or "stiff" measure & 2.5 \\
\hline Spirits mixed & Large, double, or "stiff" measure & 3.6 \\
\hline Spirits & One finger & 1 \\
\hline Vodka martini & Regular & 3 \\
\hline Tumbler (spirit) & Full & 12 \\
\hline Beer & Pint & 3 \\
\hline Sake & One flask (180 ml) & 3.6 \\
\hline A chain ... & 5 drinks & \\
\hline "Serious drinking" or "got drunk" & - & 20 \\
\hline "Lots of" & 3 drinks & - \\
\hline "Bring in the drink tray" & 2 drinks & - \\
\hline Visit to a bar, drinking & - & 10 \\
\hline
\end{tabular}


Table 2| James Bond's alcohol consumption by book and year of publication

\begin{tabular}{|c|c|c|c|c|c|}
\hline & \multirow[b]{2}{*}{$\begin{array}{l}\text { No of days } \\
\text { described }\end{array}$} & \multirow[b]{2}{*}{$\begin{array}{l}\text { Days unable } \\
\text { to drink }\end{array}$} & \multirow[b]{2}{*}{$\begin{array}{l}\text { Alcohol consumed } \\
\text { (units) }\end{array}$} & \multicolumn{2}{|c|}{ Weekly consumption } \\
\hline & & & & $\begin{array}{l}\text { Including days unable to } \\
\text { drink }\end{array}$ & $\begin{array}{c}\text { Excluding days unable to } \\
\text { drink }\end{array}$ \\
\hline Casino Royale (1953) & 25 & 21 & 73.8 & 20.7 & 129.1 \\
\hline Live and Let Die (1954) & 14 & 7 & 84.45 & 42.3 & 84.5 \\
\hline Moonraker (1955) & 5.5 & 0 & 73.6 & 93.6 & 93.6 \\
\hline Diamonds are Forever (1956) & 5 & 0 & 50 & 70 & 70 \\
\hline From Russia with Love (1957) & 8 & 0 & 106.8 & 93.45 & 93.45 \\
\hline Dr No (1958) & 13 & 8 & 51.1 & 27.5 & 71.5 \\
\hline Goldfinger (1959) & 13 & 0 & 97.4 & 52.4 & 52.4 \\
\hline For Your Eyes Only (1960) & 8 & 0 & 113.35 & 99.2 & 99.2 \\
\hline Thunderball (1961) & 5 & 0 & 52.55 & 73.6 & 73.6 \\
\hline On Her Majesty's Secret Service (1963) & 12 & 0 & 179.8 & 104.9 & 104.9 \\
\hline You Only Live Twice (1964) & 12 & 0 & 225.8 & 132 & 132 \\
\hline Man with the Golden Gun (1965) & 3 & 0 & 41.5 & 96.8 & 96.8 \\
\hline Total & 123.5 & 36 & 1150.15 & Mean 65.2 & Mean 92.0 \\
\hline
\end{tabular}




\section{Figures}

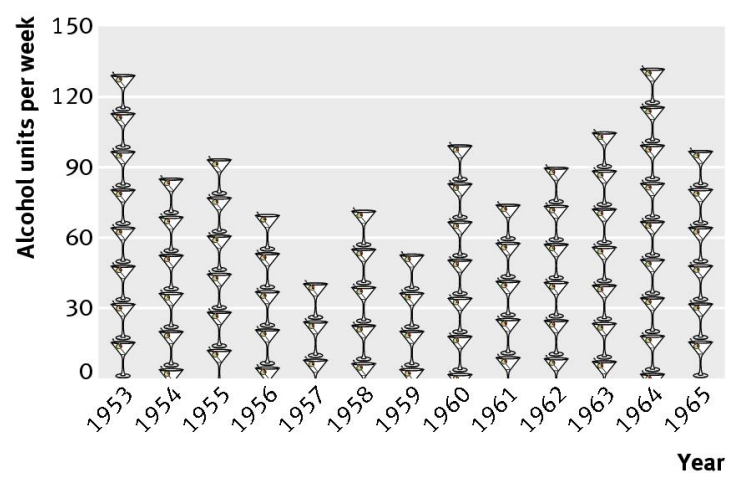

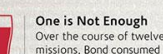

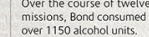

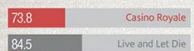

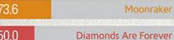

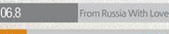

51.1

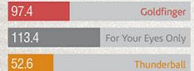

179.8

225.8 Vou Only Live Twice

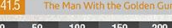

T Tomorrow's Hangover Never Dies

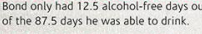

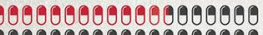

(1)

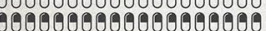

000000000000

year of book publication

JAMES BOND'S AVERACE WEEKLYY

ALCOHOL CONSUMPTIOY BY YEAB
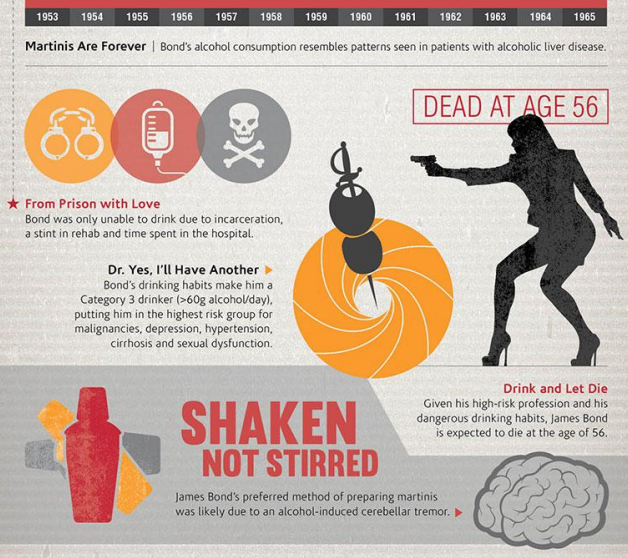

BMJ

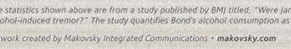

